\title{
A IMPORTÂNCIA DA EDUCAÇÃO AMBIENTAL NA INCLUSÃO DE PESSOAS COM DEFICIÊNCIA
}

\section{THE IMPORTANCE OF ENVIRONMENTAL EDUCATION IN THE INCLUSION OF PERSONS WITH DISABILITIES}

\section{Felipe da Silva Justo}

Mestrando em Educação Ambiental (PPGEA/FURG); Bacharel em Direito pela Universidade Federal do Rio Grande - FURG; integrante do Grupo de Pesquisa Cidadania, Direitos e Justiça - CIDIJUS (CNPq). Bolsista da CAPES. E-mail:

felipejusto@furg.br

Ivandro Rafael Heckler Bacharelando em Engenharia Civil na Universidade Federal do Rio Grande - FURG; Técnico em Desenho Universal (Universal Design) no Laboratório de Acessibilidade e Mobilidade Urbana LAMU. E-mail: irh_heckler@hotmail

\section{RESUMO}

Este artigo, originário dos questionamentos advindos da demanda universitária na Universidade Federal de Rio Grande (FURG), com base nos estudos promovidos pelo Núcleo de Estudos e Ações Inclusivas - NEAI, em conjunto com o Laboratório de Acessibilidade e Mobilidade Urbana - LAMU, objetiva tecer considerações sobre as legislações que orientam e regulam as construções de edificações, de uso particular ou público, assim como as obras públicas, vias públicas e espaços urbanos, no que concerne à inserção de aparatos inclusivos, permitida a sua fruição plena às pessoas com deficiência, observando que os avanços em legislações e o desenvolvimento de aparatos tecnológicos apenas alcançam parcela mínima do público a quem se destina. Nessa situação, destacase a ausência de uma proposta pautada em diálogos com a comunidade, com os usuários e usuárias das ferramentas assistivas, permitindo a construção de projetos, no qual se insere a educação ambiental, que poderá atuar na conexão dessas dicotomias, permitindo as percepções daqueles que fazem uso das ferramentas possam opinar, bem como seja estendido aos demais indivíduos da comunidade, o conhecimento necessário para compreender as dificuldades que a ausência da inclusão ocasiona na rotina das pessoas com deficiência. A educação ambiental possibilita difundir os conhecimentos específicos, publicizando e permitido que todos compreendam a importância de se pensar na inclusão, nos seus mais amplos aspectos.

Palavras-chave: Acessibilidade. Crise urbana. Educação ambiental. Mobilidade urbana.

\begin{abstract}
The purpose of this article, originated from the questions arising from university demand at the Federal University of Rio Grande - FURG, based on the studies promoted by the Nucleus of Inclusive Studies and Actions - NEAI, together with the Accessibility and Urban Mobility Laboratory - LAMU, is to elaborate considerations on how the laws legislations guide and regulate how the construction of buildings, of private or public use, as well as public works, public streets and urban spaces, in what concerns the insertion of inclusive apparatuses, allowed its full enjoyment to the observing that advances in legislation and the development of technological devices only reach a minimum portion of the target audience. In this situation, highlights to an absence of a proposal for a dialogue with the community, with users and auxiliary tools, allowing for construction projects, not allowing the users and the tools to act on dichotomies, allowing perceptions on those who use the tools may seem, as if they were the occasional evidence of the community, what is needed to understand the difficulties that the lack of awareness in the routine of people with disabilities. Environmental Education makes it possible to disseminate specific knowledge, publicizing and allowing everyone to understand the importance of thinking about inclusion, in its broadest aspects.
\end{abstract}

Keywords: Accessibility. Urban crisis. Environmental education. Urban mobility. 


\title{
INTRODUÇÃO
}

O presente artigo tem como proposta apontar que a existência de um aparato normativo, a exemplo das Leis 13.146/15 e 10.098/00, não basta para permitir a ampla e plena inclusão das pessoas com deficiência, observando que serão abordadas apenas as questões referentes à mobilidade urbana, conforme descrito nos artigos $1^{\circ}$ e $2^{\circ}$ da Lei 10.098 (BRASIL, 2000):

\begin{abstract}
Art. $1^{\circ}$. Esta Lei estabelece normas gerais e critérios básicos para a promoção da acessibilidade das pessoas portadoras de deficiência ou com mobilidade reduzida, mediante a supressão de barreiras e de obstáculos nas vias e espaços públicos, no mobiliário urbano, na construção e reforma de edifícios e nos meios de transporte e de comunicação.

Art. $2^{\text {o. }}$ Para os fins desta Lei são estabelecidas as seguintes definições:

I - acessibilidade: possibilidade e condição de alcance para utilização, com segurança e autonomia, de espaços, mobiliários, equipamentos urbanos, edificações, transportes, informação e comunicação, inclusive seus sistemas e tecnologias, bem como de outros serviços e instalações abertos ao público, de uso público ou privados de uso coletivo, tanto na zona urbana como na rural, por pessoa com deficiência ou com mobilidade reduzida;

II - barreiras: qualquer entrave, obstáculo, atitude ou comportamento que limite ou impeça a participação social da pessoa, bem como o gozo, a fruição e o exercício de seus direitos à acessibilidade, à liberdade de movimento e de expressão, à comunicação, ao acesso à informação, à compreensão, à circulação com segurança, entre outros, classificadas em:

a) barreiras urbanísticas: as existentes nas vias e nos espaços públicos e privados abertos ao público ou de uso coletivo;

b) barreiras arquitetônicas: as existentes nos edifícios públicos e privados;

c) barreiras nos transportes: as existentes nos sistemas e meios de transportes;

d) barreiras nas comunicações e na informação: qualquer entrave, obstáculo, atitude ou comportamento que dificulte ou impossibilite a expressão ou o recebimento de mensagens e de informações por intermédio de sistemas de comunicação e de tecnologia da informação;
\end{abstract}

Conforme esclarece a alínea III do parágrafo $2^{\circ}$ da Lei 10.098 (BRASIL, 2000), a pessoa com deficiência é aquela que tem qualquer "[...] impedimento de longo prazo de natureza física, mental, intelectual ou sensorial, o qual, em interação com uma ou mais barreiras, pode obstruir sua participação plena e efetiva na sociedade em igualdade de condições com as demais pessoas”, bem como explicita a alínea IV do parágrafo $2^{\circ}$ da mesma lei, ao tratar que a pessoa com mobilidade reduzida é

[...] aquela que tenha, por qualquer motivo, dificuldade de movimentação, permanente ou temporária, gerando redução efetiva da mobilidade, da flexibilidade, da coordenação motora ou da percepção, incluindo idoso, gestante, lactante, pessoa com criança de colo e obeso.

Além das legislações infraconstitucionais, o art. 227, § 2º da Carta Constitucional (BRASIL, 1988), também dispõe sobre normas de construção dos logradouros e dos edifícios de uso público e de fabricação de veículos de transporte coletivo, a fim de garantir acesso adequado às pessoas portadoras de deficiência, visando garantir a reserva de espaços e direitos, no intuito de dar plena eficácia ao que trata a Constituição Federal (BRASIL, 1988) no caput do seu artigo $5^{\circ}$, ao dizer que 
todos são iguais perante a lei, sem distinção de qualquer natureza.

Para maiores especificações, coube ao Poder Público direcionar e proporcionar suporte legal, como o Decreto n. 5.296 (BRASIL, 2004), que trata em seu artigo $2^{\circ}$, inciso I, a acessibilidade como

[...] condição para utilização, com segurança e autonomia, total ou assistida, dos espaços, mobiliários e equipamentos urbanos, das edificações, dos serviços de transporte e dos dispositivos, sistemas e meios de comunicação e informação, por pessoa portadora de deficiência ou com mobilidade reduzida;

Em linha contínua, estabelece ainda em seu artigo 10, caput, que a implantação da acessibilidade arquitetônica e urbanística deve estar de acordo com normativas quando cita que

[...] A concepção e a implantação dos projetos arquitetônicos e urbanísticos devem atender aos princípios do desenho universal, tendo como referências básicas as normas técnicas de acessibilidade da ABNT, a legislação específica e as regras contidas neste Decreto.

Atrelado ao embasamento legal supramencionado, amparado por normas e leis, cabe aos profissionais das áreas afins obterem o conhecimento necessário para aplicação e efetivação de aspectos relacionados à promoção da acessibilidade, quando eles não fornecidos em sua formação, assim como também citado no artigo 10 do Decreto n. 5.296 (BRASIL, 2004), no qual consta que

[...] Caberá ao Poder Público promover a inclusão de conteúdos temáticos referentes ao desenho universal nas diretrizes curriculares da educação profissional e tecnológica e do ensino superior dos cursos de Engenharia, Arquitetura e correlatos.

Assim, é evidente que há amparo legal para tratar das questões de mobilidade urbana para as pessoas com deficiência. Todavia, em que pese esse referido suporte legal, importante salientar que está no âmbito de "dever ser", enquanto resta pendente sua plena efetivação no plano dos fatos. Para um aprofundamento apropriado, trataremos da crise urbana, que vem a ser o resultado de uma expansão desordenada e sem planejamento das áreas urbanas das cidades brasileiras.

No que se refere à educação ambiental, é importante pontuar que possui imprescindível protagonismo para atuar no sentido pedagógico, englobando conceitos amplos, permitindo que se compreenda a importância de oferecer à população os conhecimentos pertinentes à inclusão, na forma em que esse "ambiente" habitado permita uma existência harmônica, buscando eliminar as desigualdades e barreiras, tanto as físicas quanto as que sustentam pensamentos retrógrados e preconceituosos, como descreve Zacarias:

[...] a partir de um enfoque crítico, a Educação Ambiental poderá contribuir para a formação de cidadãos conscientes, aptos para se decidirem a atuar na realidade 
socioambiental de um modo comprometido com a vida, com o bem-estar de cada um e da sociedade local e global (2000, p. 34).

Essa conexão que a educação ambiental permite alcançar é um dos meios que buscamos utilizar, ao permear áreas que não são comumente próximas.

\section{O que é a crise urbana}

Nas palavras de Maricato (2015, p. 17), “[...] a existência das cidades precede o capitalismo". Como sabido, os recursos públicos, advindos das receitas e impostos, são escassos enquanto as necessidades da administração pública, inclusive as urbanas, são ilimitadas. Por consequência, o rápido crescimento das cidades não consegue ser adequadamente administrado, podendo-se afirmar que vivemos uma crise urbana por conta do crescimento desordenado.

Num breve remonte histórico, no Brasil, apesar de sempre existirem as cidades, a concentração de pessoas nunca suplantou os números do campo até poucos anos atrás. Ocorreu, então, uma maior imigração, destacando-se a população nordestina rumo a São Paulo, fugindo da seca, fome e dificuldades financeiras, em busca do sonho de uma vida mais digna, emprego e possibilidade de mudar suas perspectivas. Isso, infelizmente, ocorreu foi a manutenção da miserabilidade desses indivíduos, que acabam marginalizados e subutilizados como mão de obra barata, assim como ocorre na maioria das situações de êxodo rural.

Segundo projeções da Organização das Nações Unidas (ONU) (United Nations - UN, 2014), em 2020, o Brasil será composto por aproximadamente $88 \%$ de população urbana e $12 \%$ na área rural, e essa diferença irá aumentar ainda mais, como os dados exemplificam: em 1960, a população rural era de 40 milhões e a urbana 15 milhões, mas, em 2016, a população rural se reduziu para 29 milhões, e população urbana salta, exponencialmente, para 178 milhões. Posta essa projeção, sem dúvidas, aterrorizante, que demonstra o inchaço extremo das zonas urbanas, trazendo toda uma problemática, poluição, esgotamento de recursos, propagação de doenças, danos ao solo e uma selva de concreto, que exclui as demais espécies, animais e vegetais, o que é demonstrado por Guimarães quando discorre sobre o homem e a natureza:

Nas sociedades atuais o ser humano afasta se da natureza. [...] O ser humano, totalmente desintegrado do todo, não percebe mais as relações de equilíbrio da natureza. Age de forma totalmente desarmônica sobre o ambiente, causando grandes desequilíbrios ambientais [...] (1995, p. 12).

A necessidade de uma transformação do agir dos homens e mulheres da nossa sociedade, que baseados nesse modelo de consumo desenfreado, está promovendo um esgotamento dos "recursos", fazendo perceber o risco que o planeta e, por consequência, a espécie humana correm, 
de forma que novas propostas surgiram, visando à "preservação": empresas verdes, sustentáveis, selos de qualidade, créditos de carbono - mas condutas adotadas apenas para garantir e manter o consumo e, por meio disso, manter e desencadear o aumento das desigualdades, pois apenas uma fração de pessoas usufrui com os lucros que adimplidos nessa exploração não mais desenfreada, mas "controlada".

Isso porque as formas de poluição são diversas, e cada agente contribui de um modo, nas capacidades que lhe cabem, de forma que é absurdo comparar uma mineradora poluidora com um pequeno pescador que enceta sua atividade em período proibido (defeso): são atividades que poluem e afetam o equilíbrio natural, mas devem ser observadas em perspectivas baseadas na proporcionalidade do dano. Reigota discorre acerca dessa situação:

Os impactos ambientais que provocamos com o nosso estilo de vida são diferentes e diferenciados e precisam ser enfatizados e não camuflados na afirmativa simplificadora de que o homem destrói o meio ambiente (2009, p. 50, grifo do autor).

Observadamente, Maricato (2015, p. 22) aponta que os capitais, em cada momento histórico e conforme os ciclos econômicos, almejam, de modo articulado, moldar as cidades conforme suas conveniências, numa aliança. Entretanto, como todo processo histórico, existem inúmeros fatores que, de modo contrário ou favorável, direcionam, guiam e, algumas vezes, até freiam os investimentos e avanços, de modo contraditório, mas não incomum, haja vista as dissonâncias dos objetivos dos grupos que conduzem e administram os interesses do mercado, nas suas inúmeras facetas e agentes.

Entretanto, como referido pela autora, algumas vezes esses agentes acabam por ter interesses diversos, a exemplo, os promotores imobiliários e proprietários de terras que possuíam interesses contrários aos capitais industriais, como acontecido em alguns momentos marcantes da história das cidades dos países centrais do capitalismo. Claro que essas colidências podem advir de outros acontecimentos, como a luta social por melhores salários, condições de trabalho e de vida (MARICATO, 2015).

$\mathrm{Na}$ busca por melhores condições, os agentes humanos dos centros urbanos acabam por pressionar e serem vistos como uma parcela do mercado que possui poder de compra, gerando uma acirrada disputa de sobrevivência, resultando na segregação daqueles incapazes de se manterem produtivos e rentáveis. É a seleção natural do capitalismo.

\section{Educação ambiental inclusiva}

Como apontado, é possível que a Educação Ambiental promova a inclusão, por meios 
pedagógicos e utilizando-se de suas funcionalidades, nos meios escolares, acadêmicos, políticos e também nas comunidades, como aponta Reigota,

A educação ambiental deve orientar-se para a comunidade, para que ela possa [...] auxiliar e incentivar o cidadão e a cidadã a participarem da resolução dos problemas e da busca de alternativas no seu cotidiano de realidades específicas [..] influir decisivamente para isso, quando forma cidadãos e cidadãs conscientes dos seus direitos e deveres. Tendo consciência e conhecimento da problemática global e atuando na sua comunidade e viceversa haverá uma mudança na vida cotidiana que, se não é de resultados imediatos, visíveis, também não será sem efeitos concretos (1996, p. 18-19).

Importante salientar que não há meios rápidos de trabalhar o processo inclusivo de pessoas com deficiência na sociedade. Para efetivar de modo célere, foi utilizado o aparato legislativo, por meio de leis que ofereceram benefícios a empresas que contratassem porcentagem de pessoas com deficiência para seus quadros de empregados, bem como houve a reserva legal de cargos públicos, conforme disciplina o artigo 37, no seu inciso VIII: “[...] a lei reservará percentual dos cargos e empregos públicos para as pessoas portadoras de deficiência e definirá os critérios de sua admissão" (BRASIL, 2015).

Para incluir a pessoa com deficiência no mercado de trabalho, o requerente precisa fazer com que o ambiente esteja de acordo para recebê-la, com isso cumprindo o disposto na legislação, conforme preceitua o parágrafo $2^{\circ}$ do artigo 42 da Lei 13.146 (BRASIL, 2015):

$\S 2^{\circ} \mathrm{O}$ poder público deve adotar soluções destinadas à eliminação, à redução ou à superação de barreiras para a promoção do acesso a todo patrimônio cultural, observadas as normas de acessibilidade, ambientais e de proteção do patrimônio histórico e artístico nacional.

Concomitantemente ao exposto pela lei supracitada, vem a concepção apresentada por Müller, ao demonstrar que os objetivos da educação ambiental são:

1- Fazer com que os indivíduos ou grupos sociais tomem maior consciência dos problemas e das características ambientais, locais e globais, sensibilizando-os para essas questões;

2- contribuir para a consciência da diversidade de experiências que devem ser somadas em prol do coletivo e para a compreensão fundamental do meio ambiente e dos problemas a ele relacionados;

3- contribuir para o comprometimento real das pessoas com os valores ambientais e sintam interesse e preocupação com natureza, motivadas de tal modo que possam participar ativamente nos projetos coletivos locais e regionais de melhoria e de proteção da qualidade ambiental, com reflexos imediatos na qualidade de vida das pessoas;

4- tornar consciente de que o verdadeiro objetivo do desenvolvimento é melhorar a qualidade de vida das pessoas. É um processo que torna possível aos seres humanos perceberem seu potencial, obter autoconfiança e uma vida plena, com dignidade e satisfação. O crescimento econômico é um importante componente do desenvolvimento, porém não pode ser um objetivo isolado, nem tampouco prosseguir indefinidamente. $\mathrm{O}$ desenvolvimento só será verdadeiro quando melhorar nossa vida em todos os aspectos, e a Educação Ambiental deve ser direcionada a esse objetivo (2000, p. 24-25).

\section{Como bem retrata Silva Filho:}


É preciso fomentar uma educação ambiental dos próprios agentes, uma mudança de habitus, para que o resultado das lides que envolvam o meio ambiente tragam, com tintas fortes, aquilo que se espera de uma sociedade que respeite o vínculo-limite entre o homem e a natureza. Não há dúvida que se trata um de jogo de potentes interesses, onde os dominantes não irão declinar de suas posições e visões do direito (2013, p. 13).

Observadamente, a proposta da educação ambiental, nesse viés, por meio de ações inclusivas, é permitir que pessoas com deficiência possam também ser participes em programas e ações de proteção ao meio ambiente, pois também são componentes de uma sociedade voltada ao consumismo, que ocasiona impactos e interferência na natureza.

Tal alegação coaduna com os objetivos da educação ambiental, não apenas na sua definição enquanto ramo de ensino, mas, no inteiro contexto, ao permitir que se alcance um grupo de indivíduos que possui competências e saberes, realizando uma conexão, de forma que a própria educação ambiental seja ampliada, alcançando um resultado em si mesma, como bem descrito no Tratado de Educação Ambiental para Sociedades Sustentáveis e Responsabilidade Global:

A educação ambiental deve promover a cooperação e o diálogo entre indivíduos e instituições, com a finalidade de criar novos modos de vida, baseados em atender às necessidades básicas de todos, sem distinções étnicas, físicas, de gênero, idade, religião, classe ou mentais.

A educação ambiental deve integrar conhecimentos, aptidões, valores, atitudes e ações. Deve converter cada oportunidade em experiências educativas de sociedades sustentáveis (2011).

Salienta-se a dificuldade de percepção da dificuldade do outro quando não se possui o mínimo de empatia e conhecimento das dificuldades que cada um precisa superar ou lidar, diariamente. Assim, é imprescindível que aqueles que tratam da educação ambiental na academia compreendam essa problemática, permitindo que aqueles desconhecedores das dificuldades possam ser iluminados por essa percepção, uma vez que, como é demonstrado, aqueles que vivenciam e estão próximos daqueles que necessitam superar as barreiras, sejam arquitetônicas, urbanísticas, no transporte ou nas comunicações, passam a compreender melhor e, assim, podem difundir à comunidade tais experiências.

\section{Acessibilizar o ambiental e ambientalizar o acessível}

Estabelecendo uma melhor abrangência e compreensão do que é inclusão, faz-se necessário determinar quem é aquele que deverá ser incluído, pois a simples menção do termo não define nem mesmo limita o seu alcance ou como alcançará, de forma que a Convenção Internacional da Organização das Nações Unidas dos Direitos da Pessoa com Deficiência (CDPD) (BRASIL, 2009) estabelece que: pessoas com deficiência são aquelas que têm impedimentos de longo prazo de 
natureza física, mental, intelectual ou sensorial, os quais, em interação com diversas barreiras, podem obstruir sua participação plena e efetiva na sociedade em igualdades de condições com as demais pessoas.

Elencado ao conceito da CDPD, podemos partir para o conceito de inclusão, que é definido, segundo Sassaki, como

[...] o processo pelo qual a sociedade se adapta para poder incluir, em seus sistemas sociais gerais, pessoas com necessidades especiais e, simultaneamente estas se preparam para assumir seus papéis na sociedade. A inclusão social constitui, então, um processo bilateral no qual as pessoas, ainda excluídas, e a sociedade buscam, em parceria, equacionar problemas, decidir sobre soluções e efetivar a equiparação de oportunidades para todos (1997, p. 42).

Assim, percebem-se na sociedade tais avanços sociais, no que se referem às políticas inclusivas e percepções de acessibilidade, onde passa a ser compreendido como "normal" uma rampa ou piso podotátil, como pontuado por Sassaki, o qual relata que

[...] estamos na fase em que cada vez mais espaços urbanos e meios de transporte já estão sendo planejados e construídos de tal forma que neles não se nota nada de especial. Isto constitui um dos sinais do surgimento de uma sociedade inclusiva (1997, p. 142),

Para maior compreensão da acessibilidade, Sassaki a fraciona em dimensões, ponderando que

As seis dimensões são: arquitetônica (sem barreiras físicas), comunicacional (sem barreiras na comunicação entre pessoas), metodológica (sem barreiras nos métodos e técnicas de lazer, trabalho, educação etc.), instrumental (sem barreiras instrumentos, ferramentas, utensílios etc.), programática (sem barreiras embutidas em políticas públicas, legislações, normas etc.) e atitudinal (sem preconceitos, 2 estereótipos, estigmas e discriminações nos comportamentos da sociedade para pessoas que têm deficiência). Portanto, a acessibilidade é uma qualidade, uma facilidade que desejamos ver e ter em todos os contextos e aspectos da atividade humana.

Se a acessibilidade for (ou tiver sido) projetada sob os princípios do desenho universal, ela beneficia todas as pessoas, tenham ou não qualquer tipo de deficiência. (2009, p. 1-2)..

Acessibilizar o ambiental advém da necessidade de conferir eficácia plena ao disposto no artigo 225 da Constituição Federal:

Todos têm direito ao meio ambiente ecologicamente equilibrado, bem de uso comum do povo e essencial à sadia qualidade de vida, impondo-se ao Poder Público e à coletividade o dever de defendê-lo e preservá-lo para as presentes e futuras gerações. § $1^{\circ}$ Para assegurar a efetividade desse direito, incumbe ao Poder Público:VI - promover a educação ambiental em todos os níveis de ensino e a conscientização pública para a preservação do meio ambiente (BRASIL, 1998).

Assegurando a efetividade em se ter um ambiente equilibrado, justifica-se a necessidade de acessibilizar o ambiental, que, conforme Borges (2014), significa fazer uma discussão ampla sobre 
como as mudanças no ambiente afetam a vida das pessoas com deficiência e também quais as políticas públicas ambientais que efetivamente são acessíveis e inclusivas, de forma a garantir a participação e o protagonismo dessas pessoas no cenário de discussão da sustentabilidade em igualdade de oportunidades com as demais pessoas.

Borges (2014) também questiona o inverso dessa afirmativa, ao descrever que ambientalizar o acessível significa primeiro garantir que os preceitos da educação ambiental, definidos no Tratado $^{1}$ e na PNEA ${ }^{2}$, estejam no horizonte e nas ações de entidades e nas políticas de inclusão. Da mesma forma, é essencial que a discussão esteja presente no contexto do debate conceitual, estabelecendo conexões entre deficiência, sustentabilidade e educação.

Desse modo, pressupõe-se que a ambientalização do acessível advém de um trabalho de conscientização, não apenas de valores "verdes", como ressalta Guimarães (1995), mas se questionando os valores já estabelecidos e propagados pela sociedade. Nesse aspecto, pertine aos indivíduos que vislumbram a importância da educação ambiental, ao compreenderem que, para a plena inclusão, é necessário dar espaço aos incluídos, e que esses protagonizem e propaguem suas ideias à sociedade.

Esse "espaço" (lugar de fala ${ }^{3}$ ) não é cedido, embora o comum seja não dar ouvidos quando aquele ou aquela que fala não possua um respaldo teórico sólido, no que seja “[...] tornar delirante aquela voz interior que é a voz do outro em nós" (SPIVAK apud DERRIDA, 2010, p. 125), pois esse local de fala sempre pertenceu a todos que queiram expor suas ideias, difundindo saberes, apontando dificuldades e caminhos utilizados para dividir experiências.

Assim, temos que o conceito de ambientalização do acessível é garantir espaço de manifestação e atuação, em todos os setores e aspectos da sociedade, para aquele e aquela que, com a sua deficiência ou limitação, possa expor seus conhecimentos e compreensões do mundo, sendo conferida a importância que tal percepção possui para a construção de um modelo de sociedade mais justo e inclusivo, como definido por Borges (2014, p. 132), ao dizer que "[...] pensar em sociedades sustentáveis necessariamente implica em garantir uma nova discussão sobre acessibilidade, direitos humanos e cidadania".

\section{Considerações}

A inclusão de pessoas com deficiência na sociedade, em especial no que se refere às barreiras urbanísticas, de comunicações, arquitetônicas e dificuldades de mobilidade nos centros

\footnotetext{
${ }^{1}$ Tratado de Educação Ambiental para Sociedades Sustentáveis e Responsabilidade Global.

${ }^{2}$ Política Nacional de Educação Ambiental.

${ }^{3}$ Para maior compreensão, ver Pode o subalterno falar?, de Gayatri Chakravorty Spivak, em que a autora tece criticas aos que buscam "falar pelo outro", vez que essa árdua tarefa pode ser uma forma de perpetuar a estrutura de opressão.
} 
urbanos, são, em sua maioria, causadas pelo crescimento não planejado das cidades e ausência de políticas publicas que dialoguem com as pessoas com deficiência e com as suas necessidades de deslocamento.

Esse crescimento não planejado, nomeado por Maricato (2015) como "crise urbana", assim como a ausência de políticas públicas que se atentem não em apenas ouvir as demandas, mas sim dar o espaço para que membros dos grupos afetados por essas barreiras passem a ser inclusos nas fileiras decisórias.

Essa inclusão é necessária afim de que se permita a plena efetivação dos direitos humanos, no que concerne ao princípio de igualdade entre os indivíduos, atentando-se ao exposto pelo sociólogo Boaventura de Souza Santos, ao dizer que

\begin{abstract}
Temos o direito de ser iguais quando a nossa diferença nos inferioriza; e temos o direito de ser diferentes quando a nossa igualdade nos descaracteriza. Daí a necessidade de uma igualdade que reconheça as diferenças e de uma diferença que não produza, alimente ou reproduza as desigualdades $(2003$, p. 56$)$.
\end{abstract}

É também necessário elencar a importância da inclusão da pessoa com deficiência no contexto social, nas mais diversas esferas do ambiente urbano, seja nas mais simples atividades urbanas, tal qual se deslocar num parque, até as questões de desempenho de atividades do cotidiano, sejam esportivas ou laborais, pois, além da necessidade de superar as inúmeras barreiras físicas, haverá toda uma problemática ao lidar com barreiras no trato com os demais indivíduos da sociedade, que nem sempre possuem o adequado conhecimento para se relacionar com o diferente e respeitar as especificidades e particularidades de cada pessoa e sua necessidade específica.

O mercado de trabalho é, atualmente, um ambiente de hostilidade e difícil acesso, dado o acirrado clima de competitividade e número reduzidos de vagas existentes,o que é ainda mais dificultoso para uma pessoa com deficiência, que necessita superar uma série de barreiras e dificuldades oriundas da sua condição,, razão pela qual se faz necessária a implementação de ações afirmativas.

Essas ações afirmativas visam incluir, de forma que o mercado absorva essas pessoas, permitindo que possam desempenhar funções, alcançando a plena inclusão, em atividades onde possam, sem prejuízo de sua especificidade, exercer protagonismo.

Assim, compreende-se necessária a atuação da educação ambiental, no que se refere à inclusão de pessoas com deficiência. Isso deve acontecer para que as pessoas que não possuem deficiência percebam as que possuem, compreendendo as suas dificuldades, pois é essa a celeuma que habita a sociedade: pessoas que não percebem o outro, pois esse lhes é alheio, estranho. 
Nesse contexto, advém o conceito de ambientalizar o acessível (BORGES, 2014), para que, mais do que inserir a pessoa com deficiência na sociedade, esta esteja preparada e seja capaz de recepcioná-la. É nesse contexto que desponta a importância da educação ambiental, enquanto agente capaz de conectar as partes, de forma que a inclusão ocorra nos dois sentidos, sem atritos, de forma que se equalize os polos opostos, permitindo uma relação harmoniosa entre os pares.

\section{Referências}

BORGES, Jorge Amaro de Souza. Sustentabilidade \& Acessibilidade: Educação Ambiental, inclusão e direitos da pessoa com deficiência - práticas, aproximações teóricas, caminhos e perspectivas. Brasília: 2014.

BRASIL. Constituição da República Federativa do Brasil de 1988. Disponível em: <http://www.planalto.gov.br/ccivil_03/Constituicao/Constituicao.htm>. Acesso em: 28 jul. 2017.

BRASIL. Lei $\mathbf{n}^{\mathbf{0}} \mathbf{1 0 . 0 9 8}$, de 19 de dezembro de 2000. Estabelece normas gerais e critérios básicos para a promoção da acessibilidade das pessoas portadoras de deficiência ou com mobilidade reduzida, e dá outras providências. Disponível em: <http://www.planalto.gov.br/ccivil_03/leis/110098.htm>. Acesso em: 29 jul. 2018.

Decreto $\mathrm{n}^{0}$ 5.296, de 2 de dezembro de 2004. Regulamenta as Leis $\mathrm{n}^{\text {os }} 10.048$, de 8 de novembro de 2000, que dá prioridade de atendimento às pessoas que especifica, e 10.098, de 19 de dezembro de 2000, que estabelece normas gerais e critérios básicos para a promoção da acessibilidade das pessoas portadoras de deficiência ou com mobilidade reduzida, e dá outras providências. Disponível em: <http://www.planalto.gov.br/ccivil_03/_Ato20042006/2004/Decreto/D5296.htm>. Acesso em: 27 set. 2018.

. Decreto no 6.949, de 25 de Agosto de 2009. Promulga a Convenção Internacional sobre os Direitos das Pessoas com Deficiência e seu Protocolo Facultativo, assinados em Nova York, em 30 de março de 2007. Disponível em: <http://www.planalto.gov.br/ccivil_03/_ato20072010/2009/decreto/d6949.htm>. Acesso em: 18 ago. 2018.

Ministério do Meio Ambiente. Tratado de Educação Ambiental para Sociedades Sustentáveis e Responsabilidade Global. 2011. Disponível em: <http://portal.mec.gov.br/secad/arquivos/pdf/educacaoambiental/tratado.pdf>. Acesso em: 25 ago. 2018.

Lei $\mathrm{n}^{\mathbf{0}}$ 13.146, de 06 de Julho de 2015. Estabelece normas gerais e critérios básicos para a promoção da acessibilidade das pessoas portadoras de deficiência ou com mobilidade reduzida, e dá outras providências. Disponível em: <http://www.planalto.gov.br/ccivil_03/_Ato20152018/2015/Lei/L13146.htm\#art112>. Acesso em: 20 ago. 2018.

GUIMARÃES, Mauro. A Dimensão Ambiental na Educação. Campinas: Papirus, 1995.

MARICATO, Erminia. Para entender a crise urbana. São Paulo: Expressão Popular, 2015.

MÜLLER, Jackson. Educação ambiental: diretrizes para a prática pedagógica. Porto Alegre: Famurs, 2001.

REIGOTA, Marcos. O que é educação ambiental. São Paulo: Brasiliense, 2009.

SASSAKI, R. K. Inclusão: acessibilidade no lazer, trabalho e educação. Revista Nacional de Reabilitação (Reação), São Paulo, ano XII, p. 10-16, mar./abr. 2009.

SILVA FILHO, Clêncio Braz da. Direito, justiça e meio ambiente: fundamentos para uma educação ambiental dos bacharéis. REMEA - Revista Eletrônica do Mestrado em Educação Ambiental, [S.1.], v. 27, jan. 2013. Disponível em: <https://periodicos.furg.br/remea/article/view/3248>. Acesso em: 30 jul. 2018.

SPIVAK, Gayatri Chakravorty. Pode o subalterno falar? Belo Horizonte: Editora UFMG (2010 [1985]). 
Revista Tecnologia e Ambiente, v. 25, 2019, Criciúma, Santa Catarina/SC ISSN Eletrônico 2358-9426 e ISSN Impresso 1413-8131

UNITED NATIONS. Department of Economic and Social Affairs, Population Division (2014): World Urbanization Prospects - The 2014 Revision. Disponível em: <https://esa.un.org/unpd/wup/Country-Profiles>. Acesso em: 18 jul. 2018.

ZACARIAS, R. Consumo, lixo e educação ambiental: uma abordagem crítica. Juiz de Fora: FEME, 2000. 